\title{
BMJ Open Depression and risk of hospitalisations and rehospitalisations for ambulatory care-sensitive conditions in Denmark: a population-based cohort study
}

Dimitry S Davydow, ${ }^{1}$ Morten Fenger-Grøn, ${ }^{2}$ Anette Riisgaard Ribe, ${ }^{2}$ Henrik Søndergaard Pedersen, ${ }^{2}$ Anders Prior, ${ }^{2}$ Peter Vedsted, ${ }^{2}$ Jürgen Unützer, ${ }^{1}$ Mogens Vestergaard ${ }^{2}$

To cite: Davydow DS, Fenger-Grøn M, Ribe AR, et al. Depression and risk of hospitalisations and rehospitalisations for ambulatory care-sensitive conditions in Denmark: a population-based cohort study. BMJ Open 2015;5: e009878. doi:10.1136/ bmjopen-2015-009878

- Prepublication history and additional material is available. To view please visit the journal (http://dx.doi.org/ 10.1136/bmjopen-2015009878).

Received 1 September 2015 Revised 6 October 2015 Accepted 22 October 2015

\section{(1) crossank}

${ }^{1}$ Department of Psychiatry and Behavioral Sciences, University of Washington, Seattle, Washington, USA ${ }^{2}$ Research Unit for General Practice, Department of Public Health, Aarhus University, Aarhus C, Denmark

\section{Correspondence to} Dr Dimitry S Davydow; ddavyd01@u.washington.edu

\section{ABSTRACT}

Objective: Hospitalisations for ambulatory caresensitive conditions (ACSCs), a group of chronic and acute illnesses considered not to require inpatient treatment if timely and appropriate ambulatory care is received, and early rehospitalisations are common and costly. We sought to determine whether individuals with depression are at increased risk of hospitalisations for ACSCs, and rehospitalisation for the same or another ACSC, within 30 days.

Design: National, population-based cohort study.

Setting: Denmark.

Participants: 5049353 individuals $\geq 18$ years of age between 1 January 2005 and 31 December 2013.

Measurements: Depression was ascertained via psychiatrist diagnoses in the Danish Psychiatric Central Register or antidepressant prescription redemption from the Danish National Prescription Registry. Hospitalisations for ACSCs and rehospitalisations within 30 days were identified using the Danish National Patient Register.

Results: Overall, individuals with depression were 2.35 times more likely to be hospitalised for an ACSC (95\% Cl 2.32 to 2.37 ) versus those without depression after adjusting for age, sex and calendar period, and 1.45 times more likely after adjusting for socioeconomic factors, comorbidities and primary care utilisation (95\% $\mathrm{Cl} 1.43$ to 1.46). After adjusting for ACSC-predisposing comorbidity, depression was associated with significantly greater risk of hospitalisations for all chronic (eg, angina, diabetes complications, congestive heart failure exacerbation) and acute ACSCs (eg, pneumonia) compared to those without depression. Compared to those without depression, persons with depression were 1.21 times more likely to be rehospitalised within 30 days for the same ACSC (95\% Cl 1.18 to 1.24$)$ and 1.19 times more likely to be rehospitalised within 30 days for a different ACSC (95\% Cl 1.15 to 1.23 ).

Conclusions: Individuals with depression are at increased risk of hospitalisations for ACSCs, and once discharged are at elevated risk of rehospitalisations within 30 days for ACSCs.

\section{Strengths and limitations of this study}

- A strength of our study is that we followed a nationwide, population-based cohort with nearly no loss to follow-up.

- Our use of data from a country with a national healthcare system with universal access to healthcare and a relatively homogeneous population may impact generalisability to other countries with more ethnically diverse populations and different healthcare settings.

- Although we lack data on potential mediators of an association between depression and ambulatory care-sensitive condition (ACSC)-related hospitalisations such as health-risk behaviours (eg, smoking, sedentary lifestyle), previous studies that controlled for health-risk behaviours found that the association between depression and greater risk for ACSC-related hospitalisations was independent of these factors.

- Our data lacks the degree of detail required to determine if adequate treatment for depression could moderate the adverse outcomes seen here.

\section{INTRODUCTION}

Hospitalisations for chronic illnesses and their sequelae are a major contributor to rising healthcare costs in Western societies. ${ }^{1}$ In the USA, an estimated $10 \%$ of all hospitalisations may be preventable, ${ }^{2}$ such as those for ambulatory care-sensitive conditions (ACSCs), a set of chronic (eg, diabetes with complications, congestive heart failure (CHF), chronic obstructive pulmonary disease (COPD) exacerbation) and acute illnesses (eg, bacterial pneumonia, urinary tract infection (UTI)) considered not to require inpatient treatment if patients receive timely and appropriate ambulatory care. ${ }^{3}$ Hospitalisations for ACSCs have been estimated to cost US\$31.9 billion and $£ 1.4$ 
billion in the UK annually. ${ }^{45}$ Moreover, early rehospitalisations, some of which may be due to ACSCs, are common and costly to health systems. ${ }^{6}$ With the advent of accountable care organisations in the USA and other efforts to improve healthcare delivery worldwide, health systems are increasingly trying to prevent hospitalisations for ACSCs and early rehospitalisations in an effort to reduce healthcare spending. ${ }^{7-9}$

Depression is highly prevalent worldwide, ${ }^{10}$ and is independently associated with more chronic disease sequelae, ${ }^{11}$ greater healthcare costs ${ }^{12}$ and increased mortality. ${ }^{13}$ Importantly, depression is amenable to treatment and could be a potentially modifiable risk factor for ACSC-related hospitalisations. Depression may increase hospitalisations for ACSCs through factors such as reduced adherence to chronic disease treatments and reduced self-care. ${ }^{14}$ While prior studies have found higher risk of hospitalisations for ACSCs and/or early rehospitalisations among persons with depression, they have been limited to single centre, ${ }^{15}{ }^{16}$ specific chronic disease populations, ${ }^{17}$ geographically defined health systems, ${ }^{16} 17$ and older adults. ${ }^{18}$ Furthermore, previous research on depression and risk of rehospitalisations within 30 days has not focused on potentially preventable rehospitalisations, ${ }^{15} \quad 16 \quad 18 \quad 19$ such as rehospitalisations within 30 days for an ACSC, an outcome that is arguably of particular importance to health systems and health policymakers. Also, it remains unknown whether depressed individuals are at greater risk of ACSC-related hospitalisations and rehospitalisations simply because they are more likely to have underlying chronic diseases. $^{20} 21$

Utilising data from a population-based cohort of 5 million Danish adults, we sought to determine if individuals with depression, defined by a clinical diagnosis and/or receiving antidepressant treatment, are at increased risk of hospitalisations for ACSCs after adjusting for demographics, socioeconomic factors, comorbidities (ACSC-predisposing and non-ACSC-predisposing comorbidities), and primary care utilisations. Further, we examined whether persons with depression who have been hospitalised for an ACSC are at greater risk of rehospitalisation for the same, or another ACSC, within 30 days. We hypothesised that depression would be independently associated with increased risk of hospitalisations for ACSCs as well as rehospitalisations within 30 days for either the same or a different ACSC.

\section{METHODS}

\section{Population}

We conducted a population-based cohort study of all adults $\geq 18$ years of age, alive and residing in Denmark at least 1 day between 1 January 2005 and 31 December 2013. The cohort was constructed using data from the Danish Civil Registration System, ${ }^{22}$ which includes data on sex, date of birth, vital status and emigration since 1 January 1968. In the register, Danish residents are each assigned a unique personal identification number which links to person-level data. ${ }^{22}$

\section{Primary independent variable}

Our primary independent variable of interest was depression as identified by either psychiatric diagnosis or filling at least one antidepressant prescription. Depression was treated as a time-dependent variable (ie, an individual without a recorded depression diagnosis or antidepressant prescription redemption at baseline could be diagnosed with depression or redeem an antidepressant prescription during the follow-up period, moving from the 'unexposed' to the 'exposed' group). Information on psychiatric diagnoses was obtained from the Danish Psychiatric Central Register ${ }^{23}$ (see online supplementary appendix 1), which includes diagnostic information on all psychiatric hospitalisations from 1969 onwards and outpatient specialty mental health visits from 1995 onwards. ${ }^{23}$ Prescription fills for antidepressants (ie, selective serotonin re-uptake inhibitors, monoamine oxidase inhibitors, and other non-tricyclic (TCA) antidepressants, see online supplementary appendix 1) were identified using the Danish National Prescription Registry. ${ }^{24}$ This register includes data on all prescriptions dispensed at Danish pharmacies since 1995, including purchase date and classification of drugs according to the Anatomical Therapeutic Chemical Classification. ${ }^{25}$ We excluded TCA prescriptions from our depression definition because of their frequent use for insomnia and/or pain. We also excluded bupropion or trazodone prescriptions since neither was approved for treating depression in Denmark during the study period. Individuals with schizophrenia, schizoaffective disorders or bipolar disorder were censored at date of diagnosis (see online supplementary appendix 2) and excluded from analyses.

\section{Outcomes of interest}

Our primary outcome of interest was hospitalisation for 1 of 12 ACSCs as defined by the Agency for Healthcare Research and Quality (AHRQ) (see online supplementary appendix 3). ${ }^{2}$ Register-based diagnoses were based on the Danish version of the International Classification of Diseases, 8th Revision (ICD-8) prior to 31 December 1993. ${ }^{26}$ From 1 January 1994 onwards, the Danish version of the ICD-10 $0^{27}$ was used. Since the AHRQdefined ACSCs were originally derived using ICD-9 diagnoses, we included eight AHRQ-defined ACSCs (ie, angina without concomitant cardiovascular procedures, COPD exacerbation, CHF exacerbation, diabetes with short-term complications, diabetes with long-term complications, uncontrolled diabetes, hypertension (HTN) and appendicitis with perforation) that were translated into ICD-10 diagnosis codes and validated in a previous study. ${ }^{28}$ We also included four AHRQ-defined ACSCs (ie, bacterial pneumonia, diabetes-related lower extremity amputations, UTIs and adult asthma exacerbations) based on ICD-10 codes used in prior Danish 
register-based studies. ${ }^{29-32}$ We further divided ACSCs into five 'chronic' ACSCs (ie, angina, CHF exacerbation, HTN, diabetes related, COPD/adult asthma exacerbation) and three 'acute' ACSCs (ie, appendicitis with perforation, pneumonia and UTI). We used the Danish National Patient Register, ${ }^{33}$ which contains information on all medical hospitalisations since 1 January 1977 and outpatient visits since 1 January $1995,{ }^{33}$ to obtain information on hospitalisations with principal discharge diagnoses for ACSCs occurring between 1 January 2005 and 31 December 2013. If a discharge was followed by an admission within 1 day, it was considered a transfer and counted as one admission only. We excluded hospitalisations with secondary obstetric diagnoses (ICD-10 codes: O00.0-O99.9).

Our secondary outcome of interest was rehospitalisation for an ACSC within 30 days of discharge from the initial ACSC-related hospitalisation. We counted rehospitalisations that were for the same ACSC, or for a different ACSC, using data from the Danish National Patient Register.

\section{Socioeconomic factors, comorbid medical conditions and substance abuse disorders}

Information on marital/partnered status and education was obtained from Statistics Denmark and the Danish Educational Registers, respectively (see online supplementary appendix 4). ${ }^{34} 35$ We categorised marital/partnered status as living with a partner (ie, married, registered partnership or cohabitation) or living alone (ie, living without a partner, including widows/ widowers). We classified maximum educational level attained into the following three categories based on the United Nations Educational, Scientific and Cultural Organisation's International Standard Classification of Education: low ( $<10$ years), middle ( $10-15$ years) and high ( $>15$ years) ${ }^{36}$

For the five chronic ACSCs, we defined ACSC-predisposing medical comorbidity specific for each ACSC in question (see online supplementary appendix 5). Information on ACSC-predisposing medical comorbidity and non-ACSC predisposing medical comorbidity was obtained from the Danish National Patient Register and based on Charlson comorbidity index (CCI) categories $^{37}$ (see online supplementary appendix 6) (eg, myocardial infarction as ACSC-predisposing medical comorbidity for angina hospitalisation, etc), with two exceptions. Diabetes diagnoses were obtained from the Danish National Diabetes Register between 1 January 1990 and 31 December 2013 (see online supplementary appendix 7).$^{38}$ Chronic pulmonary disease was identified as either a diagnosis based on the CCI category obtained from the Danish National Patient Register or $\geq 2$ prescription redemptions within a 6-month period for medications treating obstructive airway diseases (see online supplementary appendix 8) as obtained from the Danish National Prescription Registry. Non-ACSC predisposing medical comorbidity included all remaining CCI diagnostic categories. We did not define ACSC-predisposing medical comorbidity for the three acute ACSCs.

Data on substance abuse (excluding tobacco abuse) was obtained from the Danish Psychiatric Central Register or the Danish National Patient Register (see online supplementary appendix 9).

\section{Primary care utilisation}

We obtained information on daytime face-to-face visits with primary care physicians (PCPs) or other primary care staff from the Danish National Health Service Register, ${ }^{39}$ which has been collecting primary care administrative data since 1 January 1990 . To reduce the chances of including a primary care visit that directly resulted in an ACSC-related hospitalisation, we constructed a time-dependent variable counting the number of primary care visits from 10 to 375 days before any given day. We categorised primary care visits into three equally sized categories of low, medium or high utilisation based on observed frequencies (ie, 0-2, 3-9 or $\geq 10$ visits).

\section{Statistical analysis}

We compared individuals with depression to those without depression using Poisson regression models in order to estimate incidence rate ratios (IRRs) of hospitalisations for ACSCs and subsequent rehospitalisation within 30 days for an ACSC. We estimated corresponding 95\% CIs using cluster robust variance estimation to account for interperson correlation and dichotomy of rehospitalisation. In these analyses, our outcomes of interest were a count of the number of hospitalisations for ACSCs. Age and calendar period were adjusted for using 2-year and 1-year age and time bands, respectively. All variables (including depression status), except sex, were treated as time-dependent. Individuals contributed at-risk time from 1 January 2005 or from their 18th birthday, whichever came last, in different time bands based on the different covariate combinations they enter with during follow-up. Within each of these combinations, we counted the number of ACSC-related hospitalisations. These methods allowed us to count only ACSC-related hospitalisations that occurred after registration of a depression diagnosis and/or redemption of an antidepressant prescription. Censoring occurred at date of death, emigration, date of bipolar disorder or schizophrenia diagnosis, or on 31 December 2013, whichever came first.

For each ACSC-related hospitalisation outcome, we fitted five risk models, adjusting sequentially for demographics (ie, age, sex and calendar period), socioeconomic factors (ie, marital/partnered status and education), ACSC-predisposing medical comorbidity (with each comorbid condition entered individually), other comorbidities (ie, non-ACSC-predisposing medical comorbidity entered individually and substance abuse) and primary care utilisation. All model covariates were chosen a priori based on prior studies identifying their 
potential associations with both depression and healthcare utilisation outcomes. ${ }^{12} 161740$ To address missing data on education, we conducted multiple imputation using five imputed data sets according to methods developed by Rubin. ${ }^{41}$

We performed two pre-specified subanalyses. First, we examined whether the association between depression and risk of ACSC-related hospitalisations was modified by age. To do so, we repeated our Poisson regressions stratified by three age categories: $\leq 40,41-64$ and $\geq 65$ years. Second, we examined the associated risk of hospitalisations for chronic and acute ACSCs based on time since depression diagnosis in models adjusted for demographics.

In order to determine if an association between depression and risk of hospitalisations for ACSCs was impacted by our depression definition, we performed a prespecified sensitivity analysis in which we repeated our regressions using three different depression definitions: antidepressant prescription alone, outpatient psychiatric visit-based diagnosis alone or psychiatric hospitalisation for depression.

We fitted three models examining risk of rehospitalisation within 30 days for an ACSC. The first model was adjusted for demographics, the second included adjustment for socioeconomic factors and the third for medical and substance abuse comorbidities. Our outcome of interest in these models was time to rehospitalisation for an ACSC within 30 days of discharge from the initial ACSC-related hospitalisation. Individuals were at risk of the outcome on the day of discharge from their ACSC-related hospitalisation. All variables in these analyses excluding sex were treated as time-dependent.

We used two-sided significance tests for all analyses with statistical significance set at $\mathrm{p}<0.05$. Analyses were performed using STATA V.13 (Stata Corporation, College Station, Texas, USA).

\section{RESULTS}

We followed a cohort of 5049353 individuals for a total of 38674363 person-years at risk, including 1319896 (26.1\%) persons diagnosed with depression or who had redeemed an antidepressant prescription during the study period. Of those with depression, 1182495 $(89.6 \%)$ cases were from antidepressant prescription fills while $137401(10.4 \%)$ cases were diagnosed by mental health specialists in outpatient or inpatient contacts. The mean age at initially registered depression diagnosis was $49.1(\mathrm{SD}=19.2)$ years.

Table 1 displays the characteristics of our cohort by depression status. During the 9-year follow-up period, we identified 1255640 hospitalisations for ACSCs, including $542184(43.2 \%)$ among persons with depression. There were 71.4 ACSC-related hospitalisations per 1000 person-years among those with depression versus 23.0 per 1000 person-years among those without depression during the study period.
Compared to those without depression, the IRR for individuals with depression having any ACSC-related hospitalisation was 2.35 (95\% CI 2.32 to 2.37 ) after adjusting for demographics. This association remained robust after adjusting for socioeconomic factors, and decreased though remained significant after adjusting for possible mediators including comorbidities and PCP visits during the previous year (table 2).

In comparison to persons without depression, depression was associated with increased risk of hospitalisations for all of the chronic ACSCs even after adjusting for specific chronic ACSC-predisposing medical comorbidity (table 2), particularly for hospitalisations for angina (IRR=1.77; 95\% CI 1.73 to 1.81 ), COPD/asthma exacerbations (IRR=1.88; 95\% CI 1.84 to 1.93 ) and diabetesrelated hospitalisations (IRR $=1.83 ; 95 \%$ CI 1.77 to 1.89 ). Although these results were attenuated by adjusting for additional comorbidity and PCP visits during the previous year, depression remained independently associated with increased risk of hospitalisations for all chronic ACSCs, especially for hospitalisations for COPD/asthma exacerbations (IRR $=1.61 ; 95 \%$ CI 1.57 to 1.65$)$, and diabetes-related hospitalisations (IRR=1.69; 95\% CI 1.63 to 1.75) (table 2).

Similarly, depression was associated with increased risk of hospitalisations for all three acute ACSCs even after adjusting for medical and substance abuse comorbidities (appendicitis with perforation: IRR+1.26, 95\% CI 1.21 to 1.33; pneumonia: IRR+1.55, $95 \%$ CI 1.53 to 1.56 ; UTI: $1.74,95 \%$ CI 1.71 to 1.77$)$. These associations remained significant after adjusting for PCP visits during the preceding year.

When we stratified by age categories, we found that the association between depression and risk of hospitalisations for ACSCs was especially potent for individuals aged 40 years or younger (IRR 2.06; 1.98 to 2.13). Depression was also independently associated with increased risk of hospitalisations for ACSCs among middle-aged and older adults (table 3).

In the first year after depression diagnosis, the associated risk of hospitalisation for a chronic ACSC was nearly three times greater than those without depression (IRR 2.89; 95\% CI 2.83 to 2.96) (figure 1). The associated risk remained nearly 2.4 times greater than for those without depression (IRR 2.39, 95\% CI 2.34 to 2.43) 10 or more years after depression diagnosis. During the first year after depression diagnosis, the associated risk of hospitalisation for an acute ACSC was 3 1/ 3 times greater than for those without depression (IRR $3.33,95 \%$ CI 3.27 to 3.40 ), and the associated risk remained $2^{1 / 4}$ times higher at $\geq 10$ years after depression diagnosis (IRR 2.25; 95\% CI 2.22 to 2.29) (figure 2).

In our sensitivity analysis in which we examined whether our results regarding risk of hospitalisation for any ACSC were impacted by depression definition, we found that depression defined by antidepressant prescription alone (IRR 2.31; 95\% CI 2.28 to 2.33), outpatient psychiatric visit-based diagnosis alone (IRR 2.66; 
Table 1 Study cohort characteristics

\begin{tabular}{|c|c|c|c|c|c|c|}
\hline \multirow[b]{2}{*}{ Measure } & \multicolumn{3}{|c|}{ Depression (n=1 319 896) } & \multicolumn{3}{|c|}{ Without depression ( $n=3782713$ ) } \\
\hline & $\begin{array}{l}\text { Number of } \\
\text { hospitalisations } \\
\text { for ACSCs }\end{array}$ & $\begin{array}{l}\text { Person- } \\
\text { years at } \\
\text { risk }\end{array}$ & $\begin{array}{l}\text { Risk time } \\
\text { spent in } \\
\text { category (\%) }\end{array}$ & $\begin{array}{l}\text { Number of } \\
\text { hospitalisations } \\
\text { for ACSCs }\end{array}$ & $\begin{array}{l}\text { Person- } \\
\text { years at } \\
\text { risk }\end{array}$ & $\begin{array}{l}\text { Risk time } \\
\text { spent in } \\
\text { category (\%) }\end{array}$ \\
\hline Total & 542184 & 7596536 & 100.0 & 713456 & 31077828 & 100.0 \\
\hline \multicolumn{7}{|l|}{ Age (years) } \\
\hline$\leq 40$ & 28434 & 1771769 & 23.3 & 69350 & 11940484 & 38.4 \\
\hline $41-64$ & 158633 & 3697843 & 48.7 & 197925 & 13201867 & 42.5 \\
\hline$\geq 65$ & 355117 & 2126924 & 28.0 & 446181 & 5935477 & 19.1 \\
\hline \multicolumn{7}{|l|}{ Sex } \\
\hline Male & 231216 & 2884303 & 38.0 & 393065 & 16114603 & 51.8 \\
\hline Female & 310968 & 4712233 & 62.0 & 320391 & 14963225 & 48.2 \\
\hline \multicolumn{7}{|l|}{ Calendar period } \\
\hline 2005 & 47853 & 661461 & 8.7 & 79756 & 3564097 & 11.5 \\
\hline 2006 & 57932 & 711984 & 9.4 & 90186 & 3523904 & 11.3 \\
\hline 2007 & 46477 & 761231 & 10.0 & 67588 & 3494327 & 11.2 \\
\hline 2008 & 51896 & 805396 & 10.6 & 71465 & 3475920 & 11.2 \\
\hline 2009 & 63150 & 848956 & 11.2 & 83274 & 3452336 & 11.1 \\
\hline 2010 & 51567 & 895574 & 11.8 & 64832 & 3425594 & 11.0 \\
\hline 2011 & 74991 & 938720 & 12.4 & 89372 & 3405029 & 11.0 \\
\hline 2012 & 74535 & 972971 & 12.8 & 85424 & 3378860 & 10.9 \\
\hline 2013 & 73783 & 1000243 & 13.2 & 81559 & 3358761 & 10.8 \\
\hline \multicolumn{7}{|l|}{ Marital status } \\
\hline Living with partner & 226573 & 3585166 & 47.2 & 348530 & 15922753 & 51.2 \\
\hline Living alone & 315611 & 4011370 & 52.8 & 364926 & 15155075 & 48.8 \\
\hline \multicolumn{7}{|l|}{ Education (years) } \\
\hline$<10$ & 265781 & 2751794 & 36.2 & 312769 & 8845177 & 28.5 \\
\hline $10-15$ & 178680 & 3182588 & 41.9 & 249363 & 14267047 & 45.9 \\
\hline$\geq 16$ & 47039 & 1284597 & 16.9 & 75866 & 6318611 & 20.3 \\
\hline Missing & 50684 & 377558 & 5.0 & 75458 & 1646993 & 5.3 \\
\hline \multicolumn{7}{|l|}{ Comorbidity } \\
\hline $\mathrm{Ml}$ & 89475 & 261404 & 3.4 & 109123 & 556446 & 1.8 \\
\hline $\mathrm{CHF}$ & 118101 & 212889 & 2.8 & 137507 & 367223 & 1.2 \\
\hline Diabetes & 155739 & 761878 & 10.0 & 165161 & 1567720 & 5.0 \\
\hline $\begin{array}{l}\text { Cerebrovascular } \\
\text { disease }\end{array}$ & 126796 & 615389 & 8.1 & 98828 & 834803 & 2.7 \\
\hline $\begin{array}{l}\text { Peripheral vascular } \\
\text { disease }\end{array}$ & 79566 & 283055 & 3.7 & 70493 & 443853 & 1.4 \\
\hline $\begin{array}{l}\text { Chronic pulmonary } \\
\text { disease }\end{array}$ & 229594 & 674995 & 8.9 & 208423 & 1339308 & 4.3 \\
\hline Dementia & 44638 & 217259 & 2.9 & 19519 & 110040 & 0.3 \\
\hline $\begin{array}{l}\text { Connective tissue } \\
\text { disease }\end{array}$ & 42814 & 269168 & 3.5 & 39087 & 514840 & 1.7 \\
\hline Peptic ulcer disease & 69733 & 327298 & 4.3 & 53974 & 464831 & 1.5 \\
\hline Renal disease & 45769 & 123767 & 1.6 & 50315 & 245853 & 0.8 \\
\hline Mild liver disease & 19437 & 129645 & 1.7 & 11845 & 159553 & 0.5 \\
\hline $\begin{array}{l}\text { Moderate/severe liver } \\
\text { disease }\end{array}$ & 5287 & 27978 & 0.4 & 3516 & 34556 & 0.1 \\
\hline Paraplegia & 7123 & 31836 & 0.4 & 4893 & 46060 & 0.1 \\
\hline Cancer & 102324 & 608120 & 8.0 & 118072 & 1430995 & 4.6 \\
\hline Metastatic carcinoma & 12338 & 58013 & 0.8 & 13715 & 116930 & 0.4 \\
\hline HIV/AIDS & 1011 & 10673 & 0.1 & 998 & 22685 & 0.1 \\
\hline $\begin{array}{l}\text { Substance abuse } \\
\text { disorders }\end{array}$ & 87977 & 792810 & 10.4 & 42932 & 881074 & 2.8 \\
\hline \multicolumn{7}{|c|}{ Primary care visits in prior year } \\
\hline $0-2$ & 119055 & 2487888 & 32.7 & 196845 & 17355110 & 55.8 \\
\hline $3-9$ & 223859 & 3739020 & 49.2 & 317381 & 11687211 & 37.6 \\
\hline$\geq 10$ & 199270 & 1369628 & 18.0 & 199230 & 2035670 & 6.5 \\
\hline
\end{tabular}


Table 2 The risk of hospitalisations for ACSCs associated with depression compared to individuals without depression

\begin{tabular}{|c|c|c|c|c|c|}
\hline \multirow[b]{2}{*}{ Outcome } & \multicolumn{5}{|c|}{ Incidence rate ratio $(95 \% \mathrm{CI})$} \\
\hline & $\begin{array}{l}\text { Model 1: adjusted } \\
\text { for demographics }\end{array}$ & $\begin{array}{l}\text { Model 2: adjusted for } \\
\text { variables in model } 1 \\
\text { and socioeconomic } \\
\text { factors } †\end{array}$ & $\begin{array}{l}\text { Model 3: adjusted for } \\
\text { variables in model } 2 \text { and } \\
\text { ACSC-predisposing } \\
\text { comorbidity }\end{array}$ & $\begin{array}{l}\text { Model 4: adjusted for variables } \\
\text { in model } 3 \text { and } \\
\text { non-ACSC-predisposing } \\
\text { comorbidity } \ddagger \text { and substance } \\
\text { abuse disorders }\end{array}$ & $\begin{array}{l}\text { Model 5: adjusted for } \\
\text { variables in model } 4 \\
\text { and PCP visits in the } \\
\text { previous year }\end{array}$ \\
\hline Any ACSC & $2.35(2.32 \text { to } 2.37)^{\ddagger}$ & $2.27(2.25 \text { to } 2.29)^{\ddagger}$ & & $1.53(1.51 \text { to } 1.54)^{\ddagger}$ & $1.45(1.43 \text { to } 1.46)^{\ddagger}$ \\
\hline \multicolumn{6}{|l|}{ Type of ACSC } \\
\hline \\
\hline Angina & $2.03(1.99 \text { to } 2.08)^{\ddagger}$ & $2.00(1.96 \text { to } 2.05)^{\ddagger}$ & $1.77(1.73$ to 1.81$) \S^{\ddagger}$ & $1.52(1.49 \text { to } 1.56)^{\ddagger}$ & $1.35(1.32 \text { to } 1.38)^{\ddagger}$ \\
\hline COPD/asthma exacerbation & $3.17(3.09 \text { to } 3.24)^{\ddagger}$ & $2.97(2.90 \text { to } 3.04)^{\ddagger}$ & $1.88(1.84$ to 1.93$) \eta^{\ddagger}$ & $1.66(1.62 \text { to } 1.70)^{\ddagger}$ & $1.61(1.57 \text { to } 1.65)^{\ddagger}$ \\
\hline CHF exacerbation & $1.72(1.67 \text { to } 1.76)^{\ddagger}$ & $1.67(1.62 \text { to } 1.71)^{\ddagger}$ & $1.22(1.19 \text { to } 1.25)^{\star \star \ddagger}$ & $1.09(1.06 \text { to } 1.12)^{\ddagger}$ & $1.06(1.03 \text { to } 1.09)^{\ddagger}$ \\
\hline Diabetes related & $2.88(2.79 \text { to } 2.98)^{\ddagger}$ & $2.66(2.57 \text { to } 2.75)^{\ddagger}$ & $1.83(1.77$ to 1.89$) \mathrm{t \dagger}^{\ddagger}$ & $1.86(1.80 \text { to } 1.93)^{\ddagger}$ & $1.69(1.63 \text { to } 1.75)^{\ddagger}$ \\
\hline HTN & $1.52(1.48 \text { to } 1.57)^{\ddagger}$ & $1.48(1.44 \text { to } 1.53)^{\ddagger}$ & $1.37(1.33$ to 1.41$) \neq \ddagger^{\ddagger}$ & $1.30(1.26 \text { to } 1.34)^{\ddagger}$ & $1.18(1.14 \text { to } 1.21)^{\ddagger}$ \\
\hline \multicolumn{6}{|l|}{ Acute ACSCs } \\
\hline Appendicitis with perforation & $1.31(1.25 \text { to } 1.37)^{\ddagger}$ & $1.31(1.25 \text { to } 1.37)^{\ddagger}$ & & $1.26(1.21 \text { to } 1.33)^{\ddagger}$ & $1.21(1.16 \text { to } 1.27)^{\ddagger}$ \\
\hline Pneumonia & $2.35(2.33 \text { to } 2.38)^{\ddagger}$ & $2.29(2.27 \text { to } 2.32)^{\ddagger}$ & & $1.55(1.53 \text { to } 1.56)^{\ddagger}$ & $1.50(1.48 \text { to } 1.52)^{\ddagger}$ \\
\hline UTI & $2.38(2.34 \text { to } 2.42)^{\ddagger}$ & $2.34(2.31 \text { to } 2.38)^{\ddagger}$ & & $1.74(1.71 \text { to } 1.77)^{\ddagger}$ & $1.63(1.60 \text { to } 1.66)^{\ddagger}$ \\
\hline
\end{tabular}

${ }^{*}$ Age, sex and calendar period.

†Educational level and marital status.

$¥$ Charlson comorbidity index diagnoses not previously adjusted for.

§Adjusted for myocardial infarction.

TAdjusted for chronic pulmonary disease.

${ }^{* *}$ Adjusted for CHF.

††Adjusted for diabetes mellitus.

$\ddagger \ddagger$ Adjusted for myocardial infarction, CHF, cerebrovascular disease and peripheral vascular disease.

$\neq p<0.001$.

ACSC, ambulatory care-sensitive condition; CHF, congestive heart failure; COPD, chronic obstructive pulmonary disease; HTN, hypertension; PCP, primary care physician; UTI, urinary tract infection. 
Table 3 The effect of age on the association of depression with risk of hospitalisation for an ambulatory care-sensitive condition

\begin{tabular}{|c|c|c|c|c|}
\hline \multirow[b]{2}{*}{ Age categories, years } & \multicolumn{4}{|c|}{ Incidence rate ratio $(95 \% \mathrm{Cl})$} \\
\hline & $\begin{array}{l}\text { Adjusted for } \\
\text { demographics }\end{array}$ & $\begin{array}{l}\text { Adjusted for } \\
\text { socioeconomic factors }\end{array}$ & $\begin{array}{l}\text { Adjusted for } \\
\text { comorbidities }\end{array}$ & $\begin{array}{l}\text { Adjusted for PCP } \\
\text { visits }\end{array}$ \\
\hline$\leq 40$ & $2.88(2.78 \text { to } 3.00)^{\ddagger}$ & $2.83(2.72 \text { to } 2.93)^{\ddagger}$ & $2.34(2.25 \text { to } 2.43)^{\ddagger}$ & $2.06(1.98 \text { to } 2.13)^{\ddagger}$ \\
\hline$\overline{41-64}$ & $2.93(2.88 \text { to } 2.98)^{\ddagger}$ & 2.74 (2.69 to 2.78$) \ddagger$ & $1.94(1.91 \text { to } 1.97)^{\ddagger}$ & $1.73(1.70 \text { to } 1.76)^{\ddagger}$ \\
\hline$\geq 65$ & $2.30(2.28 \text { to } 2.32)^{\ddagger}$ & $2.18(2.15 \text { to } 2.20)^{\ddagger}$ & $1.34(1.33 \text { to } 1.36)^{\ddagger}$ & $1.31(1.30 \text { to } 1.32)^{\ddagger}$ \\
\hline
\end{tabular}

$\ddagger \mathrm{p}<0.001$.

$\mathrm{PCP}$, primary care physician.

95\% CI 2.56 to 2.77) or psychiatric hospitalisation for depression (IRR 2.69; 95\% CI 2.62 to 2.77 ) were all associated increased risk of hospitalisation for an ACSC after adjusting for demographics. These associations remained significant after adjusting for socioeconomic factors, comorbidities and PCP visits in the previous year (antidepressant prescription alone: IRR 1.44, 95\% CI 1.43 to 1.45 ; outpatient psychiatric visit-based diagnosis: IRR 1.54, 95\% CI 1.48 to 1.60; psychiatric hospitalisation for depression: IRR $1.50,95 \%$ CI 1.46 to 1.54 ).

Approximately $6.8 \%$ of all ACSC-related hospitalisations during the follow-up period were followed by an ACSC-related rehospitalisation within 30 days, of which $73 \%$ were for the same ACSC and $27 \%$ were for a different ACSC. Of the 85046 ACSC-related rehospitalisations within 30 days, 42791 (50.3\%) were among those with depression. Compared to those without depression, depression was associated with 1.36 times greater risk of rehospitalisation within 30 days for the same ACSC (95\% CI 1.32 to 1.39 ) and 1.44 times greater risk of rehospitalisation within 30 days for a different ACSC (95\% CI 1.39 to 1.49) after adjusting for age, sex and calendar period (table 4). After adjusting for socioeconomic factors and comorbidities, while attenuated, depression remained independently associated with greater risk of rehospitalisation within 30 days for the same ACSC (IRR 1.21; $95 \%$

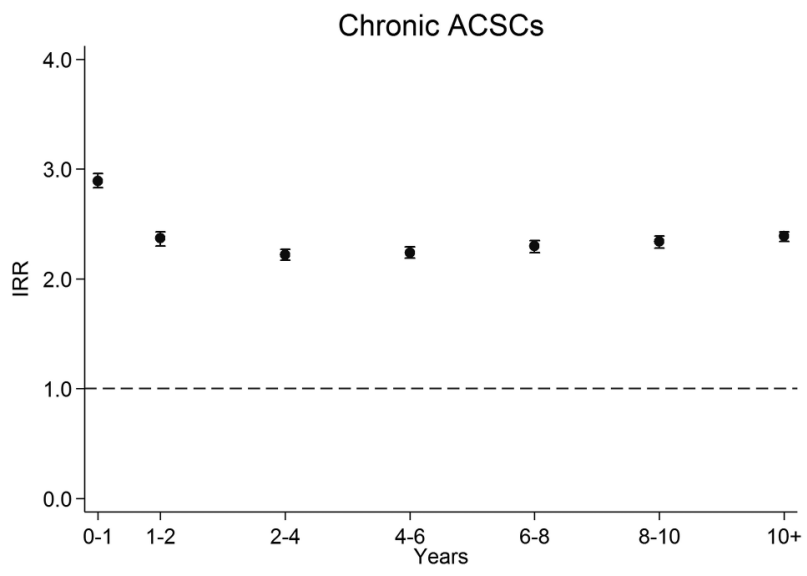

Figure 1 Risk of hospitalisation for a chronic ACSC by time since (ACSC, ambulatory care-sensitive condition; IRR, incidence rate ratio).
CI 1.18 to 1.24 ) or another ACSC (IRR 1.19; $95 \%$ CI 1.15 to 1.23$)$.

\section{DISCUSSION}

In this nationwide, population-based longitudinal study of over 5 million individuals, we found that depression was independently associated with higher risk of hospitalisations for both chronic and acute ACSCs and that the associated risk remained high for at least 10 years. To the best of our knowledge, the present study is the first to show that depression was associated with higher risk of rehospitalisation for the same or another ACSC within 30 days of an ACSC-related hospitalisation. Importantly, we identified that the associated risk of hospitalisations for ACSCs was greater among persons with depression even when we adjusted for the higher prevalence of predisposing chronic diseases in this population.

An increased risk of hospitalisation and subsequent rehospitalisation for an ACSC among depressed individuals is troubling in light of evidence that some ACSC-related hospitalisations may have negative effects on long-term functioning, cognition and mental health. ${ }^{42}$ Depression in-and-of-itself is known to increase the risk of cognitive decline and functional

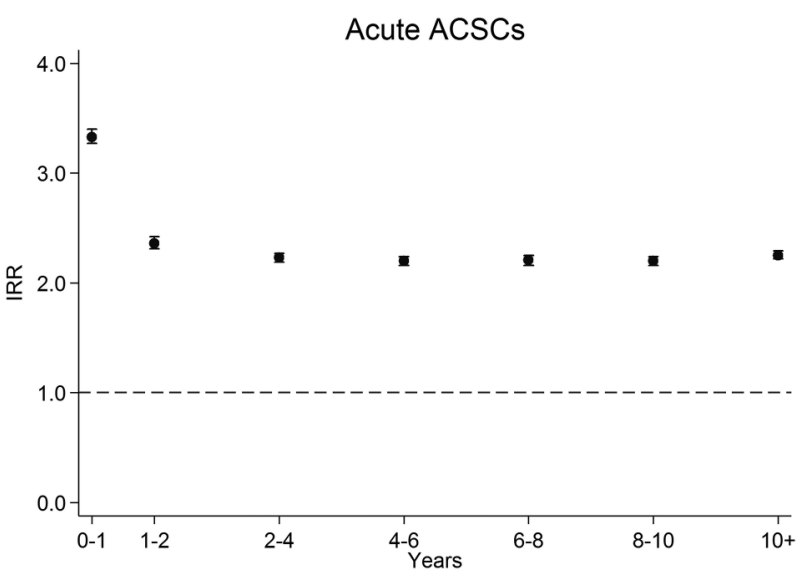

Figure 2 Risk of hospitalisation for an ACSC by time since (ACSC, ambulatory care-sensitive condition; IRR, incidence rate ratio). 
Table 4 The risk of rehospitalisation within 30 days for the same or another ACSC among those with depression compared to individuals without depression

\section{Incidence rate ratio $(95 \% \mathrm{Cl})$}

\begin{tabular}{llll}
\cline { 2 - 4 } Outcome & $\begin{array}{l}\text { Model 1: adjusted } \\
\text { for demographics }\end{array}$ & $\begin{array}{l}\text { Model 2: adjusted for variables in model 1 } \\
\text { and socioeconomic factors }\end{array}$ & $\begin{array}{l}\text { Model 3: adjusted for variables in } \\
\text { model 2, comorbidity and } \\
\text { substance abuse disorders }\end{array}$ \\
\hline Same ACSC & $1.36(1.32 \text { to } 1.39)^{\ddagger}$ & $1.34(1.31 \text { to } 1.38)^{\ddagger}$ & $1.21(1.18 \text { to } 1.24)^{\ddagger}$ \\
Another ACSC & $1.44(1.39 \text { to } 1.49)^{\ddagger}$ & $1.42(1.37 \text { to } 1.47)^{\ddagger}$ & $1.19(1.15$ to 1.23$) \ddagger$ \\
\hline fp<0.001. & &
\end{tabular}

impairment, ${ }^{43}{ }^{44}$ both of which increase the risk of ACSC-related hospitalisations. ${ }^{18}{ }^{45}$ Therefore, depressed individuals could be especially at risk for a vicious cycle of hospitalisations, rehospitalisations and rapid decline.

This study has important implications for development of interventions to prevent costly ACSC-related hospitalisations and rehospitalisations. A potential explanation for our findings is that depressed individuals may not receive timely and/or appropriate ambulatory care for chronic diseases such as diabetes or cardiovascular disease as well as acute diseases such as pneumonia or UTIs. Yet, we found that depression was independently associated with increased risk of hospitalisations for these conditions even in a country, Denmark, with universal access to primary care. Therefore, it could be reasonable to conclude that simply increasing access to primary care may not ameliorate these problems. This interpretation is supported by recent studies evaluating the impact of healthcare reform in Massachusetts that found improving access to care was not associated with reductions in ACSC-related hospitalisations or rehospitalisations within 30 days among high-risk populations. ${ }^{46} 47$

If expanding access to primary care by itself is insufficient to prevent hospitalisations for ACSCs among at-risk populations such as those with depression, then additional research is needed to identify cost-effective interventions that could reduce these potentially preventable events. One possibility is through ongoing efforts to integrate psychiatric care into primary care and other ambulatory care medical settings. Collaborative care for depression and comorbid conditions in primary care settings has been proven effective and cost-effective, ${ }^{48-53}$ and its cost-effectiveness is in part due to reductions in hospitalisations for comorbid medical conditions. ${ }^{54}$ Further studies of sufficient duration and size are needed to determine if collaborative care could prevent ACSC-related hospitalisations among individuals with depression. More research is also needed to ascertain if integrating aspects of collaborative care into existing interventions focusing on improving transitional care from the hospital back to primary care ${ }^{55} 56$ could prevent early rehospitalisations for ACSCs. Such research would be of particular interest to accountable care organisations and health policymakers aiming to reduce healthcare costs while simultaneously improving patient outcomes and overall quality of care.
Our study has several strengths and limitations. We followed a nationwide, population-based cohort with nearly no loss to follow-up. However, our use of data from a country with a national healthcare system with universal access to healthcare and a relatively homogeneous population may impact generalisability. Yet, these factors may enhance internal validity by decreasing the degree socioeconomic factors play in healthcare-seeking behaviour, and potentially suggest that our estimates may be overly conservative. Further, our depression definition was based on a combination of psychiatric diagnoses and antidepressant prescription records, potentially introducing selection bias since patients with more severe depression are more likely to be prescribed antidepressants and/or referred to psychiatrists, ${ }^{57} 58$ and is further exacerbated by inability to capture depressed individuals who have not sought treatment. ${ }^{59}$ However, our sensitivity analysis examining different depression definitions did not yield differing results, and our primary depression definition has been used in prior related research. $^{43}$

While we lack the data on potential mediators of an association between depression and ACSC-related hospitalisations such as health-risk behaviours (eg, smoking, sedentary lifestyle), previous studies in this area that controlled for health-risk behaviours found that the association between depression and greater risk for ACSC-related hospitalisations was independent of these factors. ${ }^{17} 18$ Our data lacks the degree of detail required to determine if adequate treatment for depression could moderate the adverse outcomes seen here. Also, the registers lack detail to sufficiently ascertain illness severity, so we cannot fully exclude the possibility that our findings reflect when compared to the general population, depressed individuals may present with higher acuity of medical illnesses and a greater burden of comorbidity, necessitating hospitalisation for optimal treatment.

In conclusion, in a nationwide study in Denmark, we found that compared to individuals without depression, depression was associated with increased risk of hospitalisations for ACSCs. Furthermore, once hospitalised for an ACSC, depression was associated with greater risk of rehospitalisation within 30 days for the same, or another, ACSC. Further research that clarifies the mechanisms linking depression and ACSC-related hospitalisations, and that develops interventions that prevent 
ACSC-related hospitalisations in persons with depression, is needed given the burden that recurrent hospitalisations places on individuals and society.

Acknowledgements The authors thank the late Wayne Katon, MD (19502015), for his support.

Funding This work was supported by an unrestricted grant (grant number R155-2012-11 280) from the Lundbeck Foundation.

\section{Competing interests None declared.}

Ethics approval The Danish Data Protection Agency and the Danish Health and Medicine Authority.

Provenance and peer review Not commissioned; externally peer reviewed.

Data sharing statement No additional data are available.

Open Access This is an Open Access article distributed in accordance with the Creative Commons Attribution Non Commercial (CC BY-NC 4.0) license, which permits others to distribute, remix, adapt, build upon this work noncommercially, and license their derivative works on different terms, provided the original work is properly cited and the use is non-commercial. See: http:// creativecommons.org/licenses/by-nc/4.0/

\section{REFERENCES}

1. Muka T, Imo D, Jaspers $L$, et al. The global impact of non-communicable diseases on healthcare spending and national income: a systematic review. Eur J Epidemiol 2015;30:251-77.

2. Stranges E, Stocks C. Potentially preventable hospitalizations for acute and chronic conditions, 2008. HCUP Statistical Brief \#99. Rockville, MD: Agency for Healthcare Research and Quality, 2010.

3. Agency for Healthcare Research and Quality. AHRQ quality indicators - guide to prevention quality indicators: hospital admission for ambulatory care sensitive conditions. Rockville, MD: Agency for Healthcare Research and Quality, 2001. AHRQ Pub No. 02-R0203.

4. Torio CM, Elixhauser A, Andrews RM. Trends in potentially preventable hospital admissions among adults and children, 20052010. HCUP Statistical Brief \#151. Rockville, MD: Agency for Healthcare Research and Quality, 2013.

5. The King's Fund. Emergency hospital admissions for ambulatory care-sensitive conditions: identifying the potential for reductions. http://www.kingsfund.org.uk/sites/files/kf/field/field_publication_file/ data-briefing-emergency-hospital-admissions-for-ambulatorycare-sensitive-conditions-apr-2012.pdf (accessed 20 Jun 2015).

6. Jencks SF, Williams MV, Coleman EA. Rehospitalizations among patients in the Medicare fee-for-service program. N Engl J Med 2009;360:1418-28.

7. Harrison MJ, Dusheiko M, Sutton M, et al. Effect of a national primary care pay for performance scheme on emergency hospital admissions for ambulatory care-sensitive conditions: controlled longitudinal study. BMJ 2014:349:g6423.

8. Nelson $\mathrm{KM}$, Helfrich $\mathrm{C}$, Sun $\mathrm{H}$, et al. Implementation of the patient-centered medical care home in the Veterans Health Administration: associations with patient satisfaction, quality of care, staff burnout and hospital and emergency department use. JAMA Intern Med 2014;174:1350-8.

9. Centers for Medicare and Medicaid Services. Readmissions Reduction Program. http://www.cms.gov/Medicare/Medicare-Feefor-Service-Payment/AcutelnpatientPPS/Readmissions-ReductionProgram.html (accessed 15 Jun 2015).

10. Global Burden of Disease Study Collaborators. Global, regional, and national incidence, prevalence, and years lived with disability for 301 acute and chronic diseases and injuries in 188 countries, 19902013: a systematic analysis for the Global Burden of Disease Study 2013. Lancet 2015;386:743-800.

11. Lin EH, Rutter CM, Katon W, et al. Depression and advanced complications of diabetes: a prospective cohort study. Diabetes Care 2010;33:264-9.

12. Katon WJ, Lin E, Russo JE, et al. Increased medical costs of a population-based sample of depressed elderly patients. Arch Gen Psychiatry 2003;60:897-903.

13. Sullivan MD, O'Connor $\mathrm{P}$, Feeney $\mathrm{P}$, et al. Depression predicts all-cause mortality: epidemiological evaluation from the ACCORD HRQL substudy. Diabetes Care 2012;35:1708-15.
14. Katon WJ. Clinical and health services relationships between major depression, depressive symptoms, and general medical illness. Biol Psychiatry 2003;54:216-26.

15. Mitchell SE, Paasche-Orlow MK, Forsythe SR, et al. Post-discharge hospital utilization among adult medical inpatients with depressive symptoms. J Hosp Med 2010;5:378-84.

16. Burke RE, Donzé J, Schnipper JL. Contribution of psychiatric illness and substance abuse to 30 -day readmission risk. $J$ Hosp Med 2013;8:450-5.

17. Davydow DS, Katon WJ, Lin EH, et al. Depression and risk of hospitalizations for ambulatory care-sensitive conditions in patients with diabetes. J Gen Intern Med 2013;28:921-9.

18. Davydow DS, Zivin K, Katon WJ, et al. Neuropsychiatric disorders and potentially preventable hospitalizations in a prospective cohort study of older Americans. J Gen Intern Med 2014;29:1362-71.

19. Ahmedani BK, Solberg LI, Copeland LA, et al. Psychiatric comorbidity and 30-day readmissions after hospitalization for heart failure, AMI, and pneumonia. Psychiatr Serv 2015;66:134-40.

20. Mezuk B, Eaton WW, Albrecht S, et al. Depression and type 2 diabetes over the lifespan: a meta-analysis. Diabetes Care 2008;31:2383-90.

21. Cooper DC, Trivedi RB, Nelson KM, et al. Antidepressant adherence and risk of coronary artery disease hospitalizations in older and younger adults with depression. J Am Geriatr Soc 2014;62:1238-45.

22. Pedersen CB. The Danish Civil Registration System. Scand J Public Health 2011;39(7 Suppl):22-5.

23. Mors O, Perto GP, Mortensen PB. The Danish Psychiatric Central Research Register. Scand J Public Health 2011;39(7 Suppl):54-7.

24. Kildemoes HW, Sørensen HT, Hallas J. The Danish National Prescription Registry. Scand J Public Health 2011;39(7 Suppl):38-41.

25. Skrbo A, Zulic I, Hadzic S, et al. [Anatomic-therapeutic-chemical classification of drugs]. Med Arh 1999;53:57-60.

26. World Health Organization. Manual of the International Classification of Diseases, Eighth Revision (ICD-8). Geneva, Switzerland: World Health Organization, 1967.

27. World Health Organization. Manual of the International Classification of Diseases, Tenth Revision (ICD-10). Geneva, Switzerland: World Health Organization, 1992.

28. Schiøtz M, Price M, Frølich A, et al. Something is amiss in Denmark: a comparison of preventable hospitalisations and readmissions for chronic medical conditions in the Danish Healthcare system and Kaiser Permanente. BMC Health Serv Res 2011;11:347.

29. Nielsen AG, Nielsen RB, Riis AH, et al. The impact of statin use on pneumonia risk and outcome: a combined population-based case-control and cohort study. Crit Care 2012;16:R122.

30. Jørgensen ME, Almdal TP, Faerch K. Reduced incidence of lower-extremity amputations in a Danish diabetes population from 2000 to 2011. Diabet Med 2014;31:443-7.

31. Ribe AR, Vestergaard M, Katon W, et al. Thirty-day mortality after infection among persons with severe mental illness: a population-based cohort study in Denmark. Am J Psychiatry 2015;172:776-83.

32. Andersen $A B$, Ehrenstein $\mathrm{V}$, Erichsen $\mathrm{R}$, et al. Parental inflammatory bowel disease and risk of asthma in offspring: a nationwide cohort study in Denmark. Clin Trans/ Gastroenterol 2013;4:e41.

33. Lynge E, Sandegaard JL, Rebolj M. The Danish National Patient Register. Scand J Public Health 2011;39(7 Suppl):30-3.

34. Statistics Denmark. http://www.dst.dk/en/Statistik/dokumentation/ Declarations.aspx (accessed 19 Mar 2015).

35. Jensen VM, Rasmussen AW. Danish Education Registers. Scand J Public Health 2011;39(7 Suppl):91-4.

36. United Nations Educational, Scientific and Cultural Organization. ISCED: International Standard Classification of Education. http:// www.uis.unesco.org/Education/Pages/international-standardclassification-of-education.aspx (accessed 19 Mar 2015).

37. Charlson ME, Pompei P, Ales KL. A new method for classifying prognostic comorbidity in longitudinal studies: development and validation. J Chron Dis 1987:40:373-83.

38. Carstensen B, Kristensen JK, Marcussen MM, et al. The National Diabetes Register. Scand J Public Health 2011;39(7 Suppl):58-61.

39. Andersen JS, Olivarius NF, Krasnik A. The Danish National Health Service Register. Scand J Public Health 2011;39(7 Suppl):34-7.

40. Bindman $A B$, Chattopadhyay A, Auerback GM. Interruptions in Medicaid coverage and risk for hospitalizations for ambulatory care-sensitive conditions. Ann Intern Med 2008;149:854-60.

41. Rubin DB. Multiple imputation for non-response in surveys. New York, NY: Wiley, 1987.

42. Davydow DS, Hough CL, Levine DA, et al. Functional disability, cognitive impairment, and depression after hospitalization for pneumonia. Am J Med 2013;126:615-24. 
43. Katon W, Pedersen HS, Ribe AR, et al. Effect of depression and diabetes mellitus on the risk for dementia: a national population-based cohort study. JAMA Psychiatry 2015;72:612-19.

44. Mezuk B, Edwards L, Lohman M, et al. Depression and frailty in later life: a synthetic review. Int J Geriatr Psychiatry 2012;27: 879-92.

45. Phelan EA, Borson S, Grothaus L, et al. Association of incident dementia with hospitalizations. JAMA 2012;307:165-72.

46. McCormick D, Hanchate AD, Lasser KE, et al. Effect of Massachusetts healthcare reform on racial and ethnic disparities in admissions to hospital for ambulatory care sensitive conditions: retrospective analysis of hospital episode statistics. BMJ 2015;350: h1480.

47. Lasser KE, Hanchate AD, McCormick D, et al. The effect of Massachusetts health reform on 30 day hospital readmissions: retrospective analysis of hospital episode statistics. BMJ 2014;348: g2329.

48. Unützer J, Katon W, Callahan CM, et al, IMPACT Investigators. Improving Mood-Promoting Access to Collaborative Treatment. Collaborative care management of late-life depression in the primary care setting: a randomized controlled trial. JAMA 2002;288:2836-45.

49. Lin EH, Katon W, Von Korff M, et al, IMPACT Investigators. Effect of improving depression care on pain and functional outcomes among older adults with arthritis: a randomized controlled trial. JAMA 2003;290:2428-34.

50. Katon WJ, Schoenbaum M, Fan MY, et al. Cost-effectiveness of improving primary care treatment of late-life depression. Arch Gen Psychiatry 2005;62:1313-20.
51. Gilbody S, Bower P, Fletcher J, et al. Collaborative care for depression: a cumulative meta-analysis and review of longer-term outcomes. Arch Intern Med 2006;166:2314-21.

52. Katon WJ, Lin EH, Von Korff M, et al. Collaborative care for patients with depression and chronic illness. N Engl J Med 2010;363:2611-20.

53. Katon W, Russo J, Lin EH, et al. Cost-effectiveness of a multicondition collaborative intervention: a randomized controlled trial. Arch Gen Psychiatry 2012;69:506-14.

54. Unützer J, Katon WJ, Fan MY, et al. Long-term cost effects of collaborative care for late-life depression. Am J Manag Care 2008:14:95-100.

55. Coleman EA, Parry C, Chalmers $\mathrm{S}$, et al. The care transitions intervention: results of a randomized controlled trial. Arch Intern Med 2006;166:1822-8.

56. Jack BW, Chetty VK, Anthony D, et al. A reengineered hospital discharge program to decrease rehospitalization: a randomized trial. Ann Intern Med 2009;150:178-87.

57. Gaynes BN, Rush AJ, Trivedi M, et al. A direct comparison of presenting characteristics of depressed outpatients from primary vs. specialty care settings: preliminary findings from the $S T A R^{*} D$ clinical trial. Gen Hosp Psychiatry 2005;27:87-96.

58. Cooper-Patrick L, Crum RM, Ford DE. Characteristics of patients with major depression who received care in general medical and specialty mental health settings. Med Care 1994;32:15-24.

59. Bet PM, Hugtenburg JG, Penninx BW, et al. Treatment inadequacy in primary and specialized care patients with depressive and/or anxiety disorders. Psychiatry Res 2013;210:594-600. 